\title{
UTILIZAÇÃO DE SANGUE DE ABATEDOUROS PARA PRODUÇÃO DE BACILLUS THURINGIENSIS POR FERMENTAÇÃO SUBMERSA.
}

\section{SAMARA ERNANDES ${ }^{1}$ E IRACEMA DE OLIVEIRA MORAES ${ }^{2}$.}

${ }^{1}$ Pós-graduanda em Biotecnologia do Instituto de Química da UNESP. Araraquara, SP Brasil.

${ }^{2}$ Coordenadora da Engenharia Química - Universidade Guarulhos. Docente/ Orientadora do Programa de Manejo e Conservação de Recursos - CEA/UNESP/Rio Claro.

\section{RESUMO}

Foi estudado o desenvolvimento de um microrganismo por fermentação submersa usando sangue de abatedouros de aves e suínos como principal substrato fermentativo, com a finalidade de obtenção de um biopesticida para uso contra pragas da Agricultura ou da Saúde Pública. O objetivo principal foi o de averiguar a viabilidade do sangue (resíduo) de aves e suínos como meio de cultura para Bacillus thuringiensis, bem como compará-los quanto à eficácia na produtividade. O processo foi desenvolvido em agitador rotatório, sendo as variáveis do processo fermentativo, $\mathrm{pH}$ inicial, temperatura, agitação e aeração respectivamente 7,$3 ; 30^{\circ} \mathrm{C} ; 150 \mathrm{rpm}$ e a relação $1 / 5$ entre volume de meio de cultura para volume nominal de frasco $(50 \mathrm{ml} / 250 \mathrm{ml})$. Os experimentos usando sangue como substrato, mostraram que a esterilização do sangue reduz o pH inicial do meio de cultura a níveis incompatíveis com o crescimento bacteriano e o meio de cultura não esterilizado apresentou bom crescimento do Bacillus thuringiensis, com a consequente esporulação e formação de cristais. Foram acompanhados o crescimento, através de densidade óptica, o comportamento do $\mathrm{pH}$, bem como a variação da quantidade de açúcar redutor. Os resultados obtidos permitiram concluir que o sangue de aves especialmente, por permitir crescimento e esporulação mais rápidos, mas também o de suínos, que se constituem resíduos abundantes e poluentes, podem ser utilizados com vantagens para a produção de biopesticidas de Bacillus thuringiensis. 
Palavras-chave: Bacillus thuringiensis, Resíduos Agropecuários, Sangue de Abatedouros, Processo Fermentativo.

\section{ABSTRACT}

Bacterial fermentation, using agroindustrial residues, was studied aiming to obtain a useful biopesticide to control insect pests of the Agriculture or Public Health. Literature deals with Biological Control and Microbial Control definitions, and this paper studied the development of Bacillus thuringiensis var. kurstaki using residues of animal blood as substrate. A rotary shaker was used and the growth conditions were: initial $\mathrm{pH}=$ 7.3; temperature at $30^{\circ} \mathrm{C}$; agitation rate at $150 \mathrm{rpm}$, and aeration at a $1 / 5$ volume of the culture flask. Best results using animal blood were gotten with non-sterilized blood, being the growth over chicken blood faster than in the pork blood. The $\mathrm{pH}$ behavior in this case was similar to that with culture medium recognized as good sources. It was concluded that the animal blood studied was a very good source for the development of the biopesticide using Bacillus thuringiensis, besides the advantage of the reduction of this polluent material (non costly source).

Keywords: Bacillus thuringiensis, chicken blood, pork blood, submerged fermentation.

\section{INTRODUÇÃO}

Estima-se que sejam conhecidos 1 milhão de espécies de insetos, de um total de mais de 2,5 milhões que, provavelmente, ocorrem sobre a Terra. Desse total, cerca de $10 \%$ podem ser considerados pragas da agricultura ou pragas urbanas. Assim, se cada espécie de inseto for atacada por, no mínimo um patógeno, pode-se inferir que a patologia de insetos e o controle microbiano terão, no futuro, importância relevante no controle dos insetos-praga e na cura de doenças dos insetos úteis (ALVES, 1998).

O controle microbiano de insetos utiliza microrganismos patogênicos isolados de insetos doentes durante epidemias que ocorrem naturalmente. Estes microrganismos produzem certas toxinas (esporos, células ou outros produtos) durante seu desenvolvimento e estas apresentam algumas atividades entomopatogênicas. Pesticidas microbianos são formulações que contêm os esporos, células vegetativas ou algum metabólito do desenvolvimento dos microrganismos patogênicos e que mantêm a característica de entomopatogenicidade. As bactérias, representadas principalmente pelas diferentes linhagens de Bacillus thuringiensis, são os patógenos que, nos últimos trinta anos, receberam maior atenção por parte das indústrias em todo mundo. Cerca de $50 \%$ das formulações de produtos microbianos existentes no mercado são produzidos à base das diversas espécies e variedades de Bacillus (MORAES ET AL., 1998a). 
Quando se trabalha em escala laboratorial, o meio de cultura para fermentação é geralmente preparado usando um dos meios padronizados pelos grandes laboratórios. Para isolar microrganismos ou promover o crescimento de bactérias em tubos de ensaio, o alto custo desses meios é mais do que compensado pela reprodutibilidade e facilidade de uso. Entretanto, quando grandes quantidades de meio de cultura são necessárias, é preciso encontrar fontes alternativas de nutrientes. Obviamente que tais materiais, devido ao seu baixo custo, não são puros nem padronizados quanto os seus similares laboratoriais (SALAMA E MORRIS, 1993).

A fim de minimizar o custo de produção, a maior parte das fontes nutricionais são encontradas entre bioprodutos, resíduos agrícolas ou águas residuárias industriais. Sendo assim, como fonte de carbono podem ser usados melaço de cana, melaço de beterraba e amido/fécula de cereais, raízes ou tubérculos. O nitrogênio pode ser suprido com sais de amônio, porém como fontes mais econômicas temos a água de maceração de milho, farinha e farelo de soja e caseína hidrolisada (ERNANDES E MORAES, 1997 a).

Outros sub-produtos além dos descritos foram estudados e alguns trabalhos foram desenvolvidos com sangue como substrato fermentativo (ERNANDES $\mathrm{E}$ MORAES, 1997b;1998). Dados preliminares de fermentações realizadas com $B$. thuringiensis, tendo como substrato sangue de aves e suínos sugerem que estes substratos são viáveis na medida em que promoveram o crescimento do microrganismo (ERNANDES E MORAES,1997 a), corroborando, também, o perfil de $\mathrm{pH}$, em trabalhos com "milhocina" e melaço de cana (MORAES, 1976). Trabalho com sangue de suínos, estudando o efeito da esterilização do meio de cultura composto com estes substratos, verificou pequeno crescimento de Bacillus thuringiensis em meios esterilizados (SOUZA ET AL., 1998).

O sangue recolhido por ocasião do abate dos animais nos matadouros constitui um resíduo de elevado valor nutritivo, sobretudo em virtude de suas proteínas, ricas em ácidos aminados essenciais, vitaminas e sais minerais, ao par do seu alto coeficiente de digestibilidade. Apesar do uso consagrado do sangue, como descrito anteriormente, é altamente preocupante o baixo índice de aproveitamento desse resíduo, sobretudo nos estabelecimentos menos qualificados, ainda que ele se destine a fins de alimentação animal, a fertilizante ou a certos empregos industriais. É indispensável que se faça algo para evitar o desperdício que se traduz, também, em acentuada poluição ambiental, em prejuízo econômico e no desvio de matéria-prima nobre, cujo plasma, citase na literatura, constitui-se excelente meio de cultura (SOUZA ET AL., 1998).

O objetivo deste trabalho foi comparar o desenvolvimento de Bacillus thuringiensis var. kurstaki, em meios contendo sangue de abatedouros de aves e suínos. 


\section{MATERIAL E MÉTODOS}

1. Microrganismo

Os experimentos foram realizados com o Bacillus thuringiensis var. kurstaki.

\section{Meios de cultura}

Para manutenção do microrganismo foi empregado o agar nutriente, em tubos-estoque (mantidos à temperatura de $4^{\circ} \mathrm{C}$, em refrigerador). Repiques trimestrais da cultura foram efetuados para sua manutenção. A cada repique a cultura foi mantida em estufa a $30^{\circ} \mathrm{C}$ por 72 horas, a partir do qual foi novamente estocada sob refrigeração.

\subsection{Meios de fermentação}

Para este trabalho, os resíduos foram escolhidos baseados em análise prévia de seus constituintes bioquímicos, realizados pelo laboratório do abatedouro fornecedor, bem como na proximidade da instituição fornecedora do material ao local onde o trabalho foi executado. O volume de resíduos obtido para utilização no processo foi mantido em congelador para posterior utilização, visando seu uso com as mesmas características.

Os meios de cultura foram compostos pelo sangue nas concentrações de 50 e $100 \mathrm{~g} / 1$ e glicose na concentração de $6 \mathrm{~g} / 1$, a qual proporciona um maior crescimento bacteriano, em detrimento à concentrações superiores ou inferiores que diminuem o valor de biomassa obtido (MORAES,1976).

A esterilização pelo calor em meios contendo sangue tem algumas implicações negativas para a realização de fermentações, tais como a coagulação de proteínas e o abaixamento brusco de $\mathrm{pH}$. Neste trabalho, os experimentos com sangue foram realizados sem esterilização. Contudo, houve o monitoramento através de microscopia em contraste de fase para constatar qualquer contaminação.

As fermentações foram realizadas em frascos de Erlenmeyer de $250 \mathrm{ml}$ contendo $50 \mathrm{ml}$ de meio de cultura, acondicionados em agitador-incubador, sendo 150 r.p.m. a agitação, $30^{\circ} \mathrm{C}$ a temperatura e o tempo de processo variando entre 24 e 96 horas.

\section{Inóculo}

Nos experimentos iniciais com sangue de suíno e ave optou-se por inocular usando uma suspensão de células equivalente a $3,4 \times 10^{8}$ células $/ \mathrm{ml}$. 
Foi monitorado o crescimento celular medindo-se a turbidez, em espectrofotômetro, do meio de cultura em diversos tempos de fermentação, a variação de pH do meio (pHmetro) e a variação da quantidade de açúcar redutor, através do método de Somogy-Nelson.

\section{RESULTADOS E CONCLUSÕES}

\section{COMPARAÇÃO DO PADRÃO DE CRESCIMENTO DE BACILLUS THURINGIENSIS EM SANGUE DE AVE E SANGUE DE SUÍNO.}

A Figura 1, a seguir, apresenta uma comparação do crescimento de B.thuringiensis nos dois resíduos estudados, podendo-se observar que o crescimento do microrganismo é maior e mais rápido em sangue de ave. Entretanto, o padrão de crescimento parece ser o mesmo tendo em vista o pico que ocorre em torno de 36 horas. Após esse tempo o processo em sangue de ave inicia o declínio e em sangue suíno continua um crescimento lento, quase como se fosse uma fase estacionária.

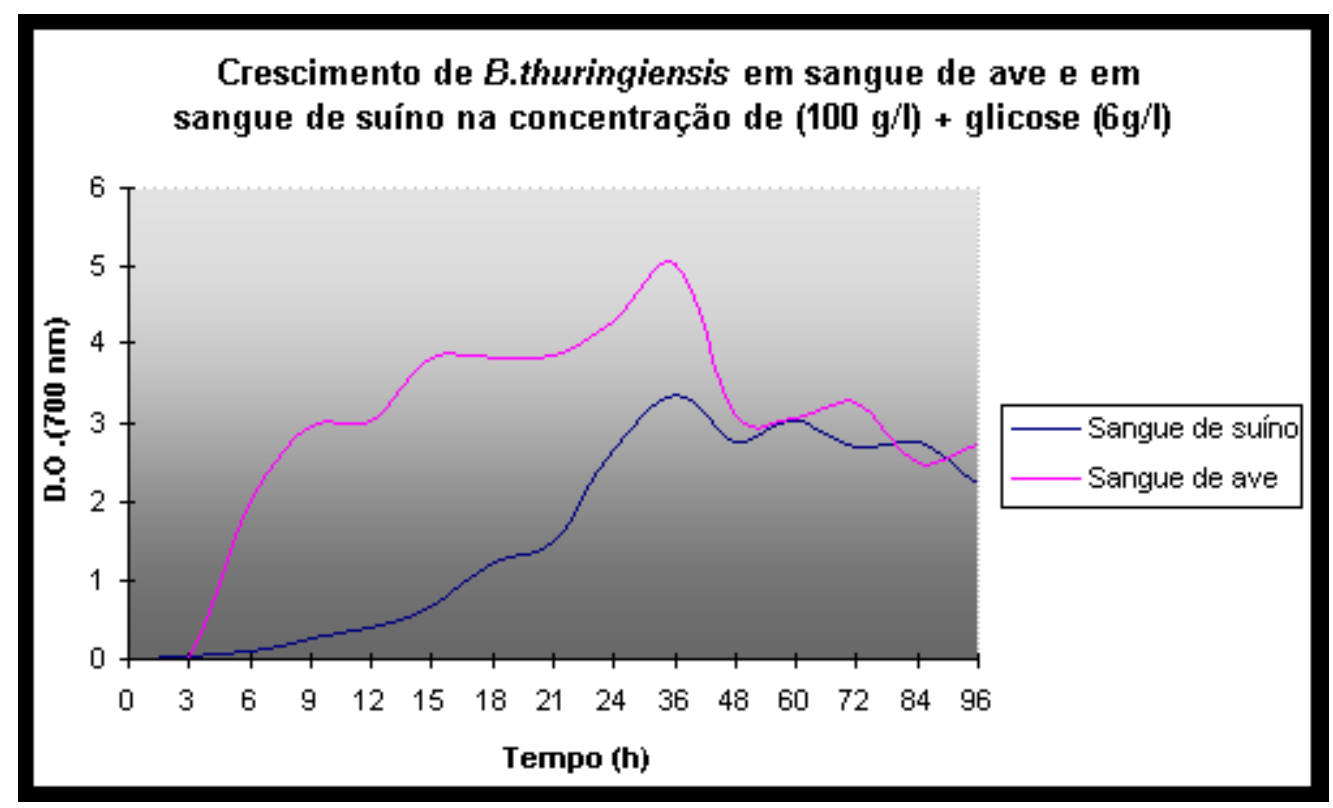

Figura 1 - Comparação do crescimento de Bacillus thuringiensis em sangue de ave e em sangue de suíno na concentração de $100 \mathrm{~g} / \mathrm{l}$ e glicose $6 \mathrm{~g} / \mathrm{l}$.

O comportamento do $\mathrm{pH}$ e do consumo de açúcar foi similar nos dois resíduos estudados. Quando se obtém o máximo valor em densidade óptica (biomassa), aproximadamente por volta de 36 horas, opostamente, verifica-se o menor valor de $\mathrm{pH}$ e um esgotamento do açúcar no meio de cultura.

Para Bacillus, nas fermentações que contam com a glicose como fonte de C, 
esta é geralmente convertida a ácidos orgânicos, com uma marcante queda do $\mathrm{pH}$ do meio de cultura. Como o baixo $\mathrm{pH}$ é desfavorável à formação adaptativa e enzimas e à ação do ciclo de TCA

(ácido tricarboxílico), a queda da concentração do carboidrato além de um determinado nível, interrompe o crescimento exponencial. Assim, a utilização dos ácidos produzidos, além da síntese de metabólitos amoniacais, faz com que o $\mathrm{pH}$ retorne à neutralidade (ou aumente) e a célula esporule (MURREL, 1967).

Nas condições experimentais empregadas, pode-se concluir que o sangue de aves e de suínos utilizados neste trabalho podem ser usados em processos fermentativos para obtenção do bioinseticida de Bacillus thuringiensis. O uso do sangue de suíno é viável, porém o rendimento em biomassa de Bacillus thuringiensis é menor que em sangue de aves, à mesma concentração. Um maior número de concentrações deve ser estudado para efetivas comparações. Próximas pesquisas, para o desenvolvimento de uma tese de Doutorado, serão realizadas para verificar a viabilidade de uso desse bioinseticida contra Aedes aegypti, importante praga da Saúde Pública.

\section{REFERÊNCIAS BIBLIOGRÁFICAS}

ALVES, S. B. Patologia e controle microbiano: vantagens e desvantagens. In: ALVES, S. B. Controle Microbiano de Insetos. $2^{a}$ ed. Piracicaba: FEALQ, 1998. Cap.1, p. 21-37.

ERNANDES, S., MORAES, I. O. Estudos preliminares do efeito da fonte de nitrogênio no crescimento de Bacillus thuringiensis. In: $24^{\circ}$ COLÓQUIO DE INCENTIVO À PESQUISA, São José do Rio Preto. Caderno de Resumos.1997a. Sessão B Biológicas, pág. 36 .

ERNANDES, S., MORAES, I. O. Verificação do padrão de crescimento de Bacillus thuringiensis, obtido por fermentação submersa em meio de cultura composto por resíduo agroindustrial. In: II SIMPÓSIO LATINO AMERICANO DE CIÊNCIA DE ALIMENTOS, Campinas. Anais. 1997b. Pag 104.

ERNANDES, S., MORAES, I. O. Estudo comparativo do padrão de crescimento de Bacillus thuringiensis em fermentação submersa contendo sangue de ave e sangue de suíno. In: VI SIMPÓSIO DE CONTROLE BIOLÓGICO, Rio de Janeiro. Anais: Sessões de Pôsteres/Fundação Oswaldo Cruz. Rio de Janeiro: Instituto Oswaldo Cruz, 1998. Pág 90.

MORAES, I. O. Ensaios de fermentação submersa para produção de inseticida bacteriano em minifermentador. Campinas, 1976. 76 pp. Tese de Doutorado.FEA/UNICAMP.

MORAES, I. O; CAPALBO, D. M. F.; ARRUDA, R. O. M. Bactérias 
entomopatogênicas. In: ALVES, S. B. Controle Microbiano de Insetos. $2^{\mathrm{a}}$ ed. Piracicaba: FEALQ, 1998a. Cap. 12, p.383-432.

MORAES, I. O., CAPALBO, D. M. F., ARRUDA, R .O..M. Produção de bactérias entomopatogênicas. In: ALVES, S. B. Controle Microbiano de Insetos. $2^{\mathrm{a}}$ ed. Piracicaba: FEALQ, 1998b. Cap. 26, p. 815-839.

MURREL,W.G. The biochemistry of the bacterial endospore. In:.Advances in Microbial Physiology" p. 133. Acad. Press, 1967.

SALAMA, H. S., MORRIS, O. N. The use of Bacillus thuringiensis in developing countries. In: ENTWISTLE, P. F. et al. Bacillus thuringiensis, Na Environmental Pesticide: Theory and Practice. England: John Wiley \& Sons, 1993. Chap. 11, 237253.

SOUZA, K. B.; MORAES, I.O.; ERNANDES, S. Estudos dos efeitos da esterilização em meio de cultura composto de sangue de suíno na produção de Bacillus thuringiensis . Livro de Resumos. I ENEALI - Encontro Nacional de Estudantes de Engenharia de Alimentos . Viçosa/MG 1998. 